\title{
REPRESENTAÇÕES DO INTELECTUAL EM RELATO DE UM CERTO ORIENTE
}

\author{
Allison Leão \\ UFMG
}

\begin{abstract}
RESU MO
Este artigo se propõe a fazer uma leitura transversal do romance Relato de um certo Oriente, de Milton Hatoum, e Representações do intelectual, as Conferências Reith de 1993, de Edward Said. Entre outras coisas, o livro de Hatoum encena ficcionalmente uma série de conceitos e características do intelectual contemporâneo que podem ser lidos, no plano da teorização ensaística, nas conferências de Said. Entre as idéias que os aproximam, destaca-se a noção de intelectual como exilado, como sujeito à margem ou com distância crítica em relação às tradições e, ao mesmo tempo, como aquele que pode ocupar um espaço de mediação e intervenção pública. O interesse pelo "Oriente" como categoria de alteridade e a figura pública de ambos autores como intelectuais também são pontos comuns entre eles. Além disso, o fato de Hatoum ser o tradutor brasileiro das conferências de Said sugere uma afinidade político-intelectual com este último. Mas, Relato de um certo Oriente foi publicado quatro anos antes de Said ter proferido suas conferências, e isso indica que uma leitura inversa entre tradutor e traduzido também pode ser bastante profícua, como se, borgeanamente, já pudéssemos ler Edward Said em Milton Hatoum. Assim, num intercâmbio de vozes, conceito e prática que parece ser cara aos dois autores, tentaremos ouvir ecos de ambos na obra de um e de outro.
\end{abstract}

\section{PALAVRAS-CHAVE}

Intelectual. Milton Hatoum. Edward Said. Alteridade.

\begin{abstract}
Relato de um certo Oriente (1989), de Milton Hatoum, é o tipo de obra que sugere uma complexidade de temas, uma rede de significações a partir da qual se podem percorrer inúmeros caminhos de sentidos e igualmente variadas abordagens temáticas, cada uma destas uma ponta de fio que remete a outro fio. Uma análise de Luis Alberto Brandão Santos, por exemplo, reconhece que a questão do imigrante é o tema fundamental desse romance ${ }^{1} \mathrm{e}$, mesmo assim, a fecunda reflexão do crítico abre seu olhar para aspectos que subjazeriam a este tema, tais quais a tradução, a margem, o "exílio da [na] língua", as relações inter-semióticas entre as linguagens escrita, oral e corporal. Maria Zilda Ferreira
\end{abstract}

${ }^{1}$ SANTOS. Trocas culturais na América Latina, p. 53. 
Cury, por sua vez, abordou o Relato tendo em vista a questão da alteridade, num artigo, ${ }^{2}$ e do feminino, noutro. ${ }^{3}$ No primeiro texto, Maria Zilda chama atenção para o fato de que o romance de Hatoum, tendo tematizado a imagem do imigrante, abre ainda leque para conceitos como: "identidade, tradução cultural, entre-lugar, memória, metalinguagem, além de outros". ${ }^{4}$ Assim, a profusão temática do escritor amazonense parece estar marcada pela (não-) presença daquele que migra - não necessariamente geograficamente -, daquele cuja condição principal é o exílio, o estar-em-trânsito, condição por sua vez dialetizada e dinamizada pelo olhar, pela voz e pela presença do outro. Para exemplificar, lembro ainda de Maria Zilda, desta vez por seu artigo a respeito das personagens femininas de Hatoum. Antes de relacioná-las metaforicamente com os diversos espaços em que transcorrem as narrativas do escritor - a casa, os corpos, o Oriente e o Ocidente, a floresta -, a autora fundamenta-se na proposta-adendo que Ricardo Piglia ${ }^{5}$ fez às cinco outras que elaborara Italo Calvino para a contemporaneidade, cujo cerne seria, para o autor argentino, la distancia, el desplazamiento, el cambio, termos que nos remetem de imediato à noção de alteridade: a interlocução como fator preponderante na ação literária da atualidade.

Seria, em outras palavras, a criação de um espaço para a voz do outro, para uma voz que diz o que, de outro modo talvez, não se pudesse dizer. Um lugar de condensação, uma outra cena, uma outra voz que somente como outra pode enunciar-se. A literatura representaria, então, esta possibilidade de espaço de linguagem em que é sempre o outro que vem dizer. E esse outro é o que se faz ouvir como uma forma de experiência. ${ }^{6}$

Minha proposta para este artigo é a de fazer uma leitura sobre um tema afluente do primeiro romance de Milton Hatoum: a figura do intelectual. Pretendo, no entanto, que essa leitura, num certo momento, ultrapasse a poética do romance, sua engenharia, que aliás encena muito bem os conceitos de intelectual e suas funções. Minha intenção, também sob a égide da alteridade, é de ler esses conceitos do ponto de vista do eco de um outro autor na obra de Hatoum - e aqui poderíamos igualmente dizer, sem o menor prejuízo, o eco de Hatoum na obra de um outro autor, que, já veremos, não está escolhido ao acaso. Para resumir, proponho uma leitura em contraluz de Relato de um certo Oriente e Representações do intelectual, de Edward Said, buscando ecos e diálogos entre essas duas obras. Há vários aspectos que aproximam esses dois autores e suscitam a possibilidade de uma leitura como que feita em troca de relevos entre ambos, suplementariamente. Tanto em Said quanto em Hatoum, evidencia-se o interesse pelo Oriente - lembremos de Orientalismo, daquele, e dos dois primeiros romances deste. A origem familiar de ambos remonta ao Oriente. No entanto, Oriente aqui está entendido, em consonância com a obra de ambos, não como lugar que se distingue apenas como o "outro lado do mundo", mas como conceito socialmente construído e tudo quanto possa implicar a expressão "outro lado do mundo" - esta é a tese de Said, que se pode apreender no subtítulo da obra acima referida: o Oriente como invenção do Ocidente. O Oriente de

\footnotetext{
${ }^{2}$ CURY. De orientes e relatos.

${ }^{3}$ CURY. Imigrantes e agregadas.

${ }^{4}$ CURY. Imigrantes e agregadas, p. 175.

${ }^{5}$ PIGLIA. Una propuesta para el nuevo milenio.

${ }^{6}$ CURY. Imigrantes e agregadas, p. 306.
} 
Said e de Hatoum também é encontrado "deste lado do mundo"; o outro não está longe, pois é construído também pelo mesmo, assim como o constitui imaginariamente. Por isso, o "certo Oriente" de Milton Hatoum não é localizável, já que a realidade das famílias de imigrantes oscila entre não estar numa terra e não se identificar com outra. O lugar que nasce dessa dinâmica é a memória, que confunde a própria noção de lugar, pois é ela o "certo Oriente" não localizável. Assim, o interesse de ambos autores pelo Oriente acaba por ser o interesse pela margem como lugar discursivo da não totalidade das identidades, o que pode ocorrer em qualquer parte do mundo.

Outra possibilidade de aproximação entre Said e Hatoum é a escolha de certa família de intelectuais, o desenho de uma comunidade de idéias, com influências e suplementos. Na primeira edição de Representations of Intellectual, a capa já nos dá uma medida dessa comunidade. Lá estão fotos de figuras como Sartre, Simone De Beauvoir, Virginia Woolf, entre outros, que, se não têm comportamento intelectual parecido com o de Said, ao menos lhe têm a admiração, que ademais pode ser lida nas seis conferências que compõem o livro. Adorno como exemplo de intelectual exilado é uma forte influência para Said; e Chomsky se lhe afigura como intelectual combativo e "amador", no sentido pensado por Said, como aquele que "se empenha em levantar questões morais no âmago de qualquer atividade, por mais técnica e profissionalizada que seja”. ${ }^{7}$ Já a integração de Hatoum a essa família intelectual tem nuanças ainda mais sutis. Primeiro porque, para confirmá-la, seria necessário um trabalho de mineração de conceitos no campo ficcional e uma posterior comparação com outros autores; teríamos que buscá-los nas malhas invisíveis do texto narrativo de Hatoum (não que o escrito ensaístico de Said não abra, noutro nível, essa problemática); depois, porque é a tradução o dispositivo que pode nos dar uma outra medida das influências de Hatoum. Ele é o tradutor brasileiro de Representations of Intellectual. Espero, logo mais, chegar a uma mínima conclusão sobre essa relação entre o "tradutor" e o "traduzido".

Se nossa preocupação aqui serão as representações de intelectuais em Relato de um certo Oriente, é necessário estabelecer que concepções de intelectual se tem em mente e como elas se dão na obra. Esta leitura vai guiar-se pelas concepções de Said no já citado Representações do intelectual. Para ele, as principais marcas do intelectual devem ser: o exílio, o "amadorismo", o desapego às tradições, a marginalidade, a distância crítica e a intervenção mediadora. Foi com essas idéias-chave que Said compôs as Conferências Reith de 1993. Mas toda sua obra anterior, como intervenção política, foi a aplicação desses conceitos. Por exemplo: sobre as queixas da imprensa britânica a respeito da escolha de seu nome para as Conferências, por um suposto partidarismo antiocidental, Said escreve:

O que meus livros tentavam combater era a construção de ficções como "Oriente" e "Ocidente", isso sem falar de essências radicalistas, tais como raças subjugadas, orientais, arianos, negros e outros. Longe de encorajar um sentimento de inocência original ressentida em países que tinham sofrido as devastações do colonialismo, afirmei repetidamente que tais abstrações míticas eram mentiras, assim como os vários discursos retóricos de culpabilização a que deram origem. ${ }^{8}$

\footnotetext{
${ }^{7}$ SAID. Representações do intelectual, p. 86.

${ }^{8}$ SAID. Representações do intelectual, p. 11.
} 
A distância e a crítica é que podem propiciar esse duplo olhar, avesso à culpa e à culpabilização. O que interessa para o intelectual saidiano não é a dualidade "bem ou mal"; o que realmente importa, e essa é sua principal tarefa, é a desconstrução de idéias que num certo ponto tornaram-se hegemônicas, chamadas muitas vezes de tradições. $\mathrm{O}$ exílio desse intelectual pode ser o exílio dele em relação a essas tradições. A distância e a marginalidade também dizem respeito a tais concepções dominantes e dominadoras. E a intervenção e o amadorismo são sua metodologia. Ou, mais que isso, são os princípios fundadores de sua ação.

Em Relato de um certo Oriente há uma série de narradores que num nível conceitual podem ser chamados de intelectuais. Aqui, refiro-me a bem mais que o célebre registro de Gramsci de que "todos os homens são intelectuais", mesmo que nem todos os homens desempenhem "na sociedade a função de intelectuais". ${ }^{9}$ No romance de Hatoum, os diversos narradores se aproximam da figura de intelectual inicialmente pelo uso da palavra, oral ou escrita, como aquilo que pode ressignificar tanto o mundo quanto o próprio homem que o narra. Quando os narradores do Relato contam suas perspectivas do passado, estão agindo além do nível do acontecimento, além da coisa como coisa, ou, recorrendo às palavras de Noberto Bobbio, tornam-se "alguém que não faz as coisas, mas reflete sobre as coisas, que não maneja objetos, mas símbolos”. ${ }^{10}$ Said já terá dito que as principais características da ação intelectual são o uso da linguagem como intervenção na própria linguagem e intervenção no mundo. ${ }^{11}$ Enquanto constroem suas narrativas, os narradores do romance reconstituem - provisoriamente - o passado: reconstituem-se a si mesmos. É isso que impede o desaparecimento do passado, como diz Said noutro ensaio, ${ }^{12}$ ou seu soterramento por aquilo que se institui como memória da tradição. Ao buscar o passado notadamente de forma perspectiva, os narradores criam aquela contramemória aludida por Said, aquilo que não permite que a consciência adormeça. ${ }^{13}$

Outra característica que insere os narradores de Hatoum numa perspectiva intelectual é a interlocução com o outro. Basta lembrar que, criticando o esvaziamento intelectual no mundo da informação e da especialização, Francisco de Oliveira nota que um certo "encolhimento do espaço público" na massa informacional gerou uma "privatização da vida", uma "subjetividade antipública" que têm como principal marca um olhar cego sobre o outro, ou um não-olhar, uma falta de interlocução. "Isso pode ser um total equívoco, porque o público não é apenas publicização, público é o outro pelo qual e somente através do qual se reproduz e produz conhecimento." ${ }^{14}$ Em Relato de um certo Oriente, a narrativa de cada narrador só pode ter sentido na medida em que vai interagindo com as outras vozes. Há sempre o momento em que o narrador com a palavra fica impossibilitado de continuar. Seria isso "el punto ciego de la experiencia" a que faz menção Ricardo Piglia. ${ }^{15}$

\footnotetext{
${ }^{9}$ GRAMSCI. Os intelectuais e a organização da cultura, p. 10.

${ }^{10}$ BOBBIO. Os intelectuais e o poder, p. 68.

${ }^{11}$ SAID. Representações do intelectual, p. 33.

${ }^{12}$ SAID. O papel público dos escritores, p. 47.

${ }^{13}$ SAID. O papel público dos escritores, p. 49.

${ }^{14}$ OLIVEIRA. Intelectuais, conhecimento e espaço público, p. 61.

${ }^{15}$ PIGLIA. Una propuesta para el nuevo milenio, p. 2.
} 
Ou seja, a experiência, assim como o conhecimento, só se pode realizar nesse deslizamento do mesmo para o outro. "Ese otro es el que hay que saber oír para que eso que se cuenta no sea una mera información y tenga la forma de la experiência." ${ }^{16}$ Assim, a experiência individual, ao ser tornada pública no diálogo com as outras subjetividades, passa a ser, nesse sentido, ação intelectual, pois entrelaçando-se com as demais falas ganha outros sentidos e gera novos significados para outras vozes. Deixa de estar engessada na instância do aqui-agora e passa a ser a representação dinâmica do tempo e do espaço.

O exílio também marca decisivamente o romance de Hatoum, por meio de vários personagens que experimentam esse sentimento de diversas maneiras. Há os que estão, de fato, exilados geograficamente, como os personagens vindos do Oriente; ou Dorner, o fotógrafo alemão - certamente uma das figuras de intelectual mais marcantes da obra -; a narradora inominada e seu irmão, entre outros. No entanto, mais interessante é a sutileza da idéia de exílio posta no romance. Luis Alberto Brandão Santos chamou apropriadamente atenção para isso, quando observou, em relação a Hakim, outro personagem exilado, que, mesmo experimentando o exílo concretamente, "é possível perceber que o sentimento de exílio sempre o acompanhara: a sensação de estar fora do seu espaço. Ou, ainda, de que não há o seu espaço". ${ }^{17}$ Assim, o estranhamento propiciado pelo exílio é o que perpassa todos exilados, tanto os que pegaram o avião quanto os que "ficaram". A viagem também é no tempo: "inconsolável em relação ao passado, amargo perante o presente e o futuro". ${ }^{18}$ Aqui, o outro novamente é uma noção decisiva, pois o exílio também diz respeito à percepção crucial de que há o diferente, mesmo que dele se possa fazer uma precária - e vicária apropriação. O romance é rico nessas relações de alteridade, de estranhamento e aproximação ao outro. Anastácia Socorro, empregada da casa libanesa, é ao mesmo tempo uma figura excluída e incluída no ambiente da casa. Negocia sua inserção nesse espaço, no espaço do outro, pelo seu poder de narrar e a fascinação que gera com isso. Segundo Luis Alberto, essa negociação, efetivada principalmente com a matriarca Emilie, significa "a certificação da diferença e a chance de torná-la um pouco menos hostil, a delimitação da distância e o momento fugidio de partilhar o mesmo espaço". ${ }^{19}$ Mais uma vez, é possível dizer que o outro, esse exílio do mesmo, é propiciador de conhecimento.

O exílio na/da palavra, por sua vez, é o que provoca a dinâmica no narrar. Existe o nível babélico dessa afirmativa, já muito bem explorado por Luis Alberto, que tem a ver com a polifonia do romance e com a renomeação e concomitante recognição do mundo geradas pelo estranhamento entre as línguas, pela simultânea "ponte e precipício" da tradução. ${ }^{20} \mathrm{O}$ texto de Maria Zilda também chama atenção para isso, na perspectiva de um rearranjo do mundo propiciado pelo olhar do que "vem de fora", que "pode reabilitar a capacidade de visão daquele que 'está dentro', imprimindo significações ao que já se tornou corriqueiro e que mal toca a percepção". ${ }^{21}$ Quero apenas acrescentar

\footnotetext{
${ }^{16}$ PIGLIA. Una propuesta para el nuevo milenio, p. 3. (Grifo meu).

${ }^{17}$ SANTOS. Trocas culturais na América Latina, p. 56.

${ }^{18}$ SAID. Representações do intelectual, p. 55.

${ }^{19}$ SANTOS. Trocas culturais na América Latina, p. 55.

${ }^{20}$ SANTOS. Trocas culturais na América Latina, p. 50-52, 56-57.

${ }^{21}$ CURY. De orientes e relatos, p. 167.
} 
que, na perspectiva da palavra, há no Relato um exílio da narrativa, um estranhamento em ralação ao ato de narrar. Isso se percebe nas idas e vindas da narradora inominada, seus volteios, vacilos e incertezas sobre o que contar e, principalmente, como contar, observáveis neste trecho:

Gravei várias fitas, enchi de anotações uma dezena de cadernos, mas fui incapaz de ordenar coisa com coisa. Confesso que as tentativas foram inúmeras e todas exaustivas, mas ao final de cada passagem, de cada depoimento, tudo se embaralhava em desconexas constelações de episódios, rumores de todos os cantos, fatos medíocres, datas e dados em abundância. Quando conseguia organizar os episódios em desordem ou encadear vozes, então surgia uma lacuna onde habitavam o esquecimento e a hesitação: um espaço morto que minava a seqüência de idéias. E isso me alijava do ofício necessário e talvez imperativo que é o de ordenar o relato, para não deixá-lo suspenso, à deriva, modulado pelo acaso. ${ }^{22}$

A operacionalização da ação intelectual se dá exatamente no nível da palavra. É pela palavra, com a palavra e contra a palavra que o trabalho do intelectual se move. O exílio na/da palavra significa a distância e a resistência em relação à linearidade e à tentativa de totalidade que a palavra das tradições e das ideologias busca empreender. Essa é a base para a idéia de produtividade do exílio que se encontra em Said. Se há uma dor do exílio, pelo que se perdeu, ou antes pela lembrança vívida do que está distante, assim como pela não integração ao novo lugar e a não libertação do que é o antigo, esses "distanciamentos pela metade", ${ }^{23}$ há também a suscitação de uma forma diferente de ver as coisas, uma saída de sobrevivência, um estado intermediário de relação com o mundo que corresponde ao estado intermediário de habitação do exilado. Assim, o intelectual passa "a ver as coisas não apenas como elas são, mas como se tornaram o que são". ${ }^{24} \mathrm{E}$ entre essas coisas está a palavra. Em Relato de um certo Oriente, há uma espécie de experimentação da narrativa enquanto se narra, quase como se a narradora inominada tateasse as palavras ao mesmo tempo em que as vai usando e, dessa maneira, retira delas um certo desgaste imprimido pelas tradições e pelo tempo. As digressões metalingüísticas, como as que lemos há pouco, dão uma medida disso. Mas o uso da voz do outro e a entrega da palavra ao outro, também demonstram essa desconstrução da palavra. De um lado, a palavra que diz sobre mim é a que vem do outro, é a palavra estranha, a palavra emprestada, da qual me aproprio. De outro lado, a palavra estranha, agora usurpada, reproduzida por outra voz, já não é mais tanto assim a palavra do outro. Trata-se de uma reinvenção da palavra, já que, na condição de exilados dela, "o que fazemos enquanto intelectuais tem de ser inventado porque não podemos seguir o caminho prescrito". ${ }^{25}$ Esse é tanto um dos objetivos do intelectual como seu instrumento porque, nos termos de Said, "o intelectual é obrigado a usar uma língua nacional não apenas por razões óbvias de conveniência e familiaridade, mas também porque ele espera imprimir-lhe um som particular, uma entonação especial e, finalmente, uma perspectiva que é própria dele". ${ }^{26}$ A tentativa

\footnotetext{
${ }^{22}$ HATOUM. Relato de um certo Oriente, p. 165.

${ }^{23}$ SAID. Representações do intelectual, p. 57.

${ }^{24}$ SAID. Representações do intelectual, p. 67-68.

${ }^{25}$ SAID. Representações do intelectual, p. 69.

${ }^{26}$ SAID. Representações do intelectual, p. 39.
} 
das ideologias tradicionais é de usar a língua como mantenedora das condições existentes, e ao intelectual cabe agir de dentro desse sistema lingüístico, porém a partir da operação da diferença.

Dos intelectuais representados em Relato de um certo Oriente, talvez a que condiga de maneira mais completa com as concepções de Edward Said, e aqui lemos Hatoum como eco - ou vice-versa, já sabemos -, seja a anônima narradora que inicia e finaliza o romance. Primeiro porque sua marginalidade é bastante acentuada, mas além disso é, num certo momento, escolhida. É uma personagem que, assim como seu irmão, integrase à família libanesa por adoção; suas origens familiares são nebulosas. Sabemos do encontro com sua mãe biológica, para a qual ela não dirige nenhum tipo de sentimento piegas ou sequer familiar. ${ }^{27}$ A marca do abandono torna-se um deixar-se ao abandono, talvez Said agora nos dissesse: para "manter nações e tradições à distância". ${ }^{28}$ Sua origem, portanto, já traz a impressão do silêncio, com o qual ela dialoga durante a narrativa. Dialogar com o silêncio é dialogar com o fragmento, com o sentido que falta, implica buscar dar sentido a essa falta, sem entretanto jamais alcançar a totalidade. A busca do sentido, o trabalho incessante de reflexão sobre a voz do outro é uma das principais ações intelectuais dessa narradora. A busca torna-se o próprio sentido. Sabemos mais ainda sobre sua marginalidade ao tomar conhecimento de que ela estivera internada numa clínica para alienados. É lá, à margem do mundo tido como normal, que ela inicia concretamente a reunião dos fragmentos para compor seu relato. Na janela do quarto, na clínica, ela pode contemplar "dois mundos", ${ }^{29}$ e pode, nessa posição fronteiriça, vêlos com a perspectiva de um entre-lugar. E a partir disso perceber as diferenças e as convergências entre os dois mundos, ambos lugares de solidão e de loucura. Estar na clínica - embora para lá tenha ido à revelia, o que fora marginalização compulsória, quando do internamento - torna-se uma escolha de perspectiva.

Miriam estranhava o fato de eu não sair dali o quanto antes; ela se incomodava quando lhe pedia para sentar no pátio [...] "O que te atrai para continuares aqui?", me dizia. Quis responder perguntando o que me atraía lá fora, mas preferi dizer que estava pensando numa viagem. ${ }^{30}$

O louco, assim como o intelectual, é aquele que vê o mundo distorcido, é aquele que re-vê as coisas. Ela, a narradora, parece perceber que, apesar das dores da marginalização, é a partir dela que se pode garantir uma suficiente distância crítica sobre os mundos além da margem.

A atitude deliberada de reunião das diversas vozes que compõem a narrativa de Relato de um certo Oriente aproxima bastante a narradora inominada à radicalidade da proposta saidiana de intelectual. Mesmo não sendo possível dizer que há uma fala hegemônica no romance, pois a voz dessa narradora é marcada pela hesitação e pelo murmúrio, ${ }^{31}$

\footnotetext{
${ }^{27}$ HATOUM. Relato de um certo Oriente, p. 159-160.

${ }^{28}$ SAID. Representações do intelectual, p. 37-54.

${ }^{29}$ HATOUM. Relato de um certo Oriente, p. 162.

${ }^{30}$ HATOUM.Relato de um certo Oriente, p. 162.

${ }^{31}$ SANTOS. Representações do intelectual, p. 48.
} 
ainda assim se pode afirmar que é ela a agente da costura dessas vozes, sempre vacilante, é certo - mas o projeto de sua narrativa nunca almeja a totalidade. Metáfora desse trabalho lê-se no seguinte trecho, fala da narradora anônima:

Retalhei um lençol esfarrapado para fazer alguns lenços, onde bordei as iniciais dos nomes e apelidos, e teci formas abstratas nos pedaços de pano que desejava presentear às quais não tinham nome ou não eram conhecidas através dos nomes: pessoas que nunca me olhavam, nunca se olhavam: corpos sem fala, excluídos do diálogo, e que pareciam caminhar num deserto sem Deus e sem oásis, deixando atrás de si um rastro apagado pelo vento, pelo sopro da morte. ${ }^{32}$

Não se trata mais do intelectual à Zola ou à Sartre, aquele que falava pelas multidões: essa narradora fala com o público, ou a partir do público, ou, antes de qualquer coisa, através do público e atravessada pelo público. Sua ação é mediadora. O espaço - público - que o intelectual ocupa é aquele a ser preenchido pelas vozes emudecidas. É ele que dará "identidade pública" às falas silenciadas, nos termos de Said. ${ }^{33}$ E, sobretudo, é sua ação consciente que traz à tona as inúmeras personagens-narradoras do romance. Se há expectativas e desejos postos de lado, soterrados pelos discursos dominantes, o intelectual é o agente que se encontra em "posição de possibilitar e incrementar a formulação dessas expectativas e desejos". ${ }^{34}$ A crítica de Said dirigida à teoria do fim da História e do desaparecimento das grandes narrativas, endereçada respectivamente a Fukuyama e Lyotard, ${ }^{35}$ diz respeito à preocupação do autor de Orientalismo sobre certo pensamento que disso pode derivar: de que, dissolvidos os grandes embates, tudo é particular, miudamente localizado, embate entre indivíduos, e que se o conflito é de cada um, cada qual fala por si. Mas a afasia não acabou após a queda do muro de Berlim. O acesso à palavra não se tornou democrático. $O$ intelectual age sobre essa necessidade de divulgação e expansão do discurso de um outro silenciado. Não o representa mais em sua fala. Não crê, sobretudo, que tenha autoridade para isso. Antes, empresta espaço a esse outro. E permite que essa voz-outra atravesse sua própria fala de intelectual.

Isso que Milton Hatoum encena em Relato de um certo Oriente é também o que se pode apreender de seu trabalho como tradutor de Edward Said. Só é possível ler a tradução do segundo pelo primeiro como esse dizer-a-parir-voz-alheia. Curiosamente, a publicação do romance de Hatoum é anterior às conferências de Said. Logo, borgeanamente, já podíamos ler Said no texto de Hatoum. Assim como se podem encontrar, numa análise que Said faz de Adorno como intelectual exilado, comentários que parecem ter sido escritos sobre Relato de um certo Oriente: "a essência da representação do intelectual como um exilado permanente, que se desvia tanto do velho como do novo com a mesma destreza, é um estilo de escrita amaneirado e trabalhado ao extremo. Antes de mais nada é fragmentário, convulsivo, descontínuo". ${ }^{36} \mathrm{O}$ jogo polifônico aqui

\footnotetext{
${ }^{32}$ HATOUM. Relato de um certo Oriente, 163.

${ }^{33}$ SAID. O papel público dos escritores, p 32.

${ }^{34}$ SAID. O papel público dos escritores, p. 39.

${ }^{35}$ SAID. Representações do intelectual, p. 16-17.

${ }^{36}$ SAID. Representações do intelectual, p. 64.
} 
vai ao limite quando pensamos: Adorno é comentado por Said, cuja tradução é feita por Hatoum, cuja obra encontra similitudes conceituais no pensamento de Said, que ao comentar Adorno parece estar falando de Hatoum. E o jogo poderia continuar até o infinito.

Há declaradamente a escolha de um texto a traduzir, que se dá, neste caso, por afeição e afinidade intelectual. Porém, há algo mais. Quando Hatoum traduz Said não é mais a voz deste a falar "sozinha" e diretamente a nós. Entra em cena a voz do tradutor como interlocutora em disfarce a ecoar no texto traduzido. Se for possível dizer que se lê Said pela escrita tradutora de Hatoum, é igualmente possível dizer que Hatoum já ecoava nos conceitos de Said anteriores às Conferências Reith e sobretudo na ação intelectual de Said durante sua trajetória. Assim, usando a voz do outro, a escrita original do outro, Milton Hatoum fala como que num plano subterrâneo, através de uma voz que toma emprestada no ato da tradução. E então pode-se dizer que não só Hatoum traduziu Said como também foi por Said traduzido.

\section{A}

\section{A B STRACT}

This article analyzes the novel Relato de um certo Oriente, written by Milton Hatoum, and Representations of the Intellectual: The 1993 Reith Lecture, by Edward Said. Among other things, Milton Hatoum's work presents fictionally a series of concepts and characteristics of the contemporary intellectual that could be read, on the theoretical level, in Said's lectures. Among the concepts that bring them together is the notion of the banished intellectual, as a man on the border or with a critical thought about the tradition and, at the same time, as the one that occupies a space of mediation and public intervention. Other similarities are the interest in the Orient as a category of alterity and the public character of both authors as intellectuals. Besides, the fact that Hatoum is the Brazilian translator of Said's conferences suggests a political-intellectual relationship among them. However, Relato de um certo Oriente was published four years before Said had conducted his conferences and this might indicate that a reverse reading between the translator and the translated author could also be fruitful, as if, like Borges, we could read Edward Said into Milton Hatoum. Thus, through an exchange of voices, concepts and practices that seems to be dear to both authors, we will try to hear one in the work of the other.

\section{KEYWORDS}

Intellectual. Milton Hatoum. Edward Said. Othering. 


\section{REFERÊNCIAS}

BOBBIO, Noberto. Os intelectuais e o poder: dúvidas e opções dos homens de cultura na sociedade contemporânea. São Paulo: Ed. UNESP, 1997. 187 p.

CURY, Maria Zilda Ferreira. Imigrantes e agregadas: personagens femininas na ficção de Milton Hatoum. In: DUARTE, Constância Lima; DUARTE, Eduardo de Assis; BEZERRA, Kátia da Costa (Org.). Gênero e representação na literatura brasileira. Belo Horizonte: Ed. UFMG, 2002. p. 305-318.

CURY, Maria Zilda Ferreira. De orientes e relatos. In: SANTOS, Luis Alberto Brandão; PEREIRA, Maria Antonieta. Trocas culturais na América Latina. Belo Horizonte: Ed. UFMG, 2000. p. 165-177.

GRAMSCI, Antonio. Os intelectuais e a organização da cultura. Trad. Carlos Nelson Coutinho. 9. ed. Rio de Janeiro: Civilização Brasileira, 1995. 244 p.

HATOUM, Milton. Relato de um certo Oriente. São Paulo: Companhia das Letras, 1989. $166 \mathrm{p}$.

OLIVEIRA, Francisco. Intelectuais, conhecimento e espaço público. In: MORAES, Dênis. Combates e utopias. Rio de Janeiro: Record, 2004. p. 55-67.

PIGLIA, Ricardo. Una propuesta para el nuevo milenio. Margens/Márgenes: Caderno de Cultura, Belo Horizonte, Mar del Plata, Buenos Aires, n. 2, p. 1-3, out. 2001.

SAID, Edward. O papel público dos escritores. In: MORAES, Dênis. Combates e utopias. Trad. Eliana Aguiar; Luis Paulo Guanabara. Rio de Janeiro: Record, 2004. p. 25-50.

SAID, Edward. Representações do intelectual: as Conferências Reith de 1993. Trad. Milton Hatoum. São Paulo: Companhia das Letras, 2005. 127 p.

SANTOS, Luis Alberto Brandão. Línguas estranhas. In: SANTOS, Luis Alberto Brandão; PEREIRA, Maria Antonieta. Trocas culturais na América Latina. Belo Horizonte: Ed. UFMG, 2000, p. 47-65. 